\title{
Time and Temperature Dependence of CdS Nanoparticles Grown in a Polystyrene Matrix
}

\author{
F. Antolini, ${ }^{1}$ E. Burresi, ${ }^{1}$ L. Stroea, ${ }^{1,2}$ V. Morandi, ${ }^{3}$ L. Ortolani, ${ }^{3}$ G. Accorsi, ${ }^{4}$ and M. Blosi ${ }^{5}$ \\ ${ }^{1}$ Italian National Agency for New Technologies Energy and Sustainable Economic Development (ENEA)-UTTMATF, \\ 48018 Faenza, Italy \\ ${ }^{2}$ Petru Poni Institute of Macromolecular Chemistry, 700487 Iasi, Romania \\ ${ }^{3}$ National Research Council (CNR)-IMM, 40129 Bologna, Italy \\ ${ }^{4}$ National Research Council (CNR)-ISOF, 40129 Bologna, Italy \\ ${ }^{5}$ National Research Council (CNR)-ISTEC, 48018 Faenza, Italy
}

Correspondence should be addressed to F. Antolini, francesco.antolini@enea.it

Received 27 May 2011; Accepted 29 September 2011

Academic Editor: Marinella Striccoli

Copyright ( 2012 F. Antolini et al. This is an open access article distributed under the Creative Commons Attribution License, which permits unrestricted use, distribution, and reproduction in any medium, provided the original work is properly cited.

\begin{abstract}
Luminescent CdS nanocrystals embedded in a polystyrene matrix were successfully prepared. The in situ growth of CdS QDs was realized by thermal treatment of Cd bis(thiolate)/polymer foil at different times and temperatures $\left(240^{\circ} \mathrm{C}\right.$ and $\left.300^{\circ} \mathrm{C}\right)$ of annealing, in order to evaluate their influence on the quantum dots growth process. As a general trend, the increasing of time and temperature of annealing induces a rise of the CdS nanocrystals size into the polymeric matrix. The size distribution, morphology, and structure of the CdS nanoparticles were analysed with HRTEM and XRD experiments. UV-Vis and PL data are strongly size-dependent and were used to investigate the particles' growth process, too. The CdS nanoparticles behavior in solution indicated a general trend of QDs to aggregation. This predisposition was clearly displayed by DLS measurements.
\end{abstract}

\section{Introduction}

In the last years nanocomposite materials have attracted much attention due to the synergistic combination of the quantum dots (QDs) and polymers characteristics, leading not only to the sum of the properties of organics and inorganics [1] but also to the creation of new functionalities that do not exist for either material alone [2]. These materials have been employed in several technological applications such as light emitting diodes $[3,4]$, solar cells $[5,6]$, and labels for biological use $[7,8]$. From the scientific point of view, the organic-inorganic nanocomposites represent the most advanced research field in materials science applied to polymers and innovative devices, because they combine the easy processability of polymers in terms of geometry, manipulation, and composition with the tunable functional properties of QDs.

Significant attention has been paid to the use of QDs belonging to II-VI groups (CdS, CdSe, CdTe), because their electrooptical properties could be perfectly combined with the charge transporting properties of conductive polymers. However, the mixture of these two materials is not obvious in terms of QDs distribution inside the polymer and charge transfer optimisation between the polymer and the QDs. Therefore, a possible approach to overcome these drawbacks is to grow the QDs directly inside the polymer [9], when the QDs formation is achieved by means of thermal decomposition of the precursor itself. The synthesis of CdS QDs using the thermolytical growth procedure from a singlesource precursor presents some advantages in respect to other common synthetic methods [9-11]: the precursor is easy to prepare and stable under normal conditions, its synthesis does not request any highly dangerous or expensive products and the metal and the chalcogenide atoms are in the correct stoichiometric ratio. Another interesting advantage of the combination between thermolytical process and in situ QDs synthesis is the space-selective formation of the nanocrystals using an external laser source [12-15]. This methodology, reported for the first time in [12], opened the way to the direct laser patterning of QDs, which can be 
useful for the implementation of new industrial processes in devices' manufacturing area [16].

However, the exploitation of the semiconductor nanocomposites on a new devices requests the possibility to tune the QDs' size and to optimize the interaction of nanoparticles with the polymeric matrix. Both of these goals are possible using the thermolytical QDs generation, because this methodology allows the QDs size modulation by varying the time and temperature of annealing and permits the growth of the QDs directly inside the polymer (in situ formation).

The effect of reaction conditions such as temperature of decomposition, precursor concentration, and time of annealing on physical-chemical properties of CdS QDs was already investigated [17-24]. However, a challenge still remains, because this process is not fully investigated when it takes place in a polymeric matrix. Starting from this approach, in this paper, it will be illustrated the importance of the time of annealing on the CdS QDs growth process directly into a polymer matrix (polystyrene). The aim of the study is to examine in detail the size dependence of the CdS crystallites from reaction's time at fixed temperatures, building up isotherm curves, size versus time, at $240^{\circ} \mathrm{C}$ and $300^{\circ} \mathrm{C}$, respectively. It has been obtained a general trend of size increment with reaction time, replicated for every isotherm curve.

The time course of the CdS growth was studied by means of UV-Vis absorption, photoluminescence (PL), and X-ray diffraction analysis (XRD). The Brus and Scherrer equations were used to calculate the particle size from UV-Vis and XRD spectra, respectively. Additional information about the QDs structure and their state in solution were obtained through high-resolution transmission electron microscopy (HRTEM) observation and dynamic light scattering (DLS) analysis.

\section{Materials and Methods}

All the reagents were purchased from Sigma-Aldrich and used without further purification unless indicated. The thermal properties of polystyrene $\left(M_{w}=280.000 \mathrm{~g} / \mathrm{mol}\right)$ were investigated using thermogravimetric analysis (data not shown). Polystyrene (PS) exhibits good thermal stability without decomposition up to $300^{\circ} \mathrm{C}$ (under nitrogen, $10^{\circ} \mathrm{C} / \mathrm{min}$ ); a weight loss of about $97 \%$ around the temperature of $415^{\circ} \mathrm{C}$ was observed.

2.1. Synthesis of $\mathrm{Cd}$ Bis(thiolate) Single-Source Precursor $\left[\mathrm{Cd}\left(\mathrm{S}-\left(\mathrm{CH}_{2}\right)_{11}-\mathrm{CH}_{3}\right)_{2}\right]$. The synthesis of the precursor from dodecanethiol [HS- $\left(\mathrm{CH}_{2}\right)_{11}-\mathrm{CH}_{3}$ ] and cadmium nitrate $\left[\mathrm{Cd}\left(\mathrm{NO}_{3}\right)_{2}\right]$ was performed as reported in [10]. An amount of $\mathrm{Cd}(\mathrm{NO})_{3}$ and dodecanethiol was solubilized separately in absolute ethanol at a final concentration of $0.1 \mathrm{M}$ and $0.2 \mathrm{M}$, respectively. Two aliquots of $50 \mathrm{~mL}$ of both solutions were mixed, and a white precipitate immediately appears. The suspension was stirred for one hour; the precipitate was centrifuged at $4500 \mathrm{rpm}$ for 5 minutes and washed three times with ethanol. The resulting white powder was dried over night at room temperature.
2.2. Preparation of Precursor/Polymer Nanocomposites. The preparation of the precursor/polymer foil was carried out dissolving $900 \mathrm{mg}$ of standard polystyrene in hot toluene under reflux and further addition of $300 \mathrm{mg}$ of Cd bis(thiolate) single-source precursor $(25 \% \mathrm{w} / \mathrm{w})$. The mixture was stirred until becomes clear. The solution is then poured in a Petri dish $(100 \mathrm{~mm}$ diameter $)$ and left to dry overnight.

Half of the obtained precursor/polystyrene disk was heated under vacuum at specific temperatures and times of annealing, whereas the resulted nanocomposite was dissolved in chloroform. This solution was split in two aliquots. The first half was used to obtain a new disk pouring it on a small Petri dish ( $40 \mathrm{~mm}$ diameter) and leaving it to dry. To allow an optimal disk formation, an additional amount of standard polystyrene $(150 \mathrm{mg})$ was added to the solution. The second aliquot was further purified to obtain QDs without degradation byproducts and polystyrene as reported following. For that, the solution was centrifuged at $4000 \mathrm{rpm}$ for 10 minutes in order to recover possible precipitated CdS crystals. This precipitate, if any, will be added to the final purified QDs. The supernatant was dried and resuspended in $5 \mathrm{~mL}$ of THF. After that, a volume of $40 \mathrm{~mL}$ of octane was added slowly, and the final solution was centrifuged for 10 minutes at $4000 \mathrm{rpm}$ to remove the precipitate. The organic solution was evaporated using a rotavapor, and the pellet was dissolved in $2 \mathrm{~mL}$ of chloroform.

In order to precipitate the QDs and to remove the degradation products, another $8 \mathrm{~mL}$ of acetone was added. The resulting precipitate was centrifuged for 10 minutes at $4000 \mathrm{rpm}$ and washed two times more with acetone. Finally, the precipitate was dissolved in chloroform and mixed with the recovered crystals (if any) separated at the beginning of this procedure.

These solutions were utilized for the optical, structural, and microscopic measurements.

\subsection{Structural, Optical, and Microscopic Characterization.} The XRD analysis was performed with a Philips conventional Bragg-Brentano vertical diffractometer with $\mathrm{CuK} \alpha$ radiation. The investigated $2 \theta$ range was $5-70^{\circ}$ with steps of $0.02^{\circ}$ and $7 \mathrm{~s}$ per step. The XRD spectra were analysed with the X'Pert software for phase determination, while the size determination was carried out using the WinFit program [25]. The sample preparation was performed depositing $300 \mu \mathrm{L}$ of the sample solution on the glass slide and leaving to dry in air.

The absorption spectra were measured with a UVVis spectrophotometer (Perkin Elmer Lambda 40) in the range of $350-600 \mathrm{~nm}$. The sample solutions dissolved in chloroform were dispersed on a quartz slide to obtain a thin film. The calculation of the QDs size was carried out using the Brus equation [26], and the wavelength introduced in this equation was obtained from the flex point of the CdS spectrum as determined by its first derivative [27].

The samples for photoluminescence (PL) spectra were prepared diluting $100 \mu \mathrm{L}$ of QDs solution in $3 \mathrm{~mL}$ of chloroform. Uncorrected emission spectra were obtained with 


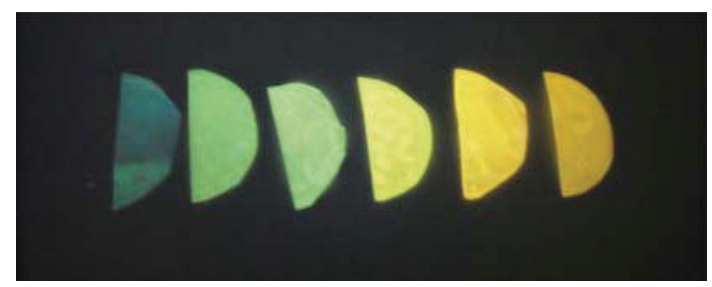

(a)

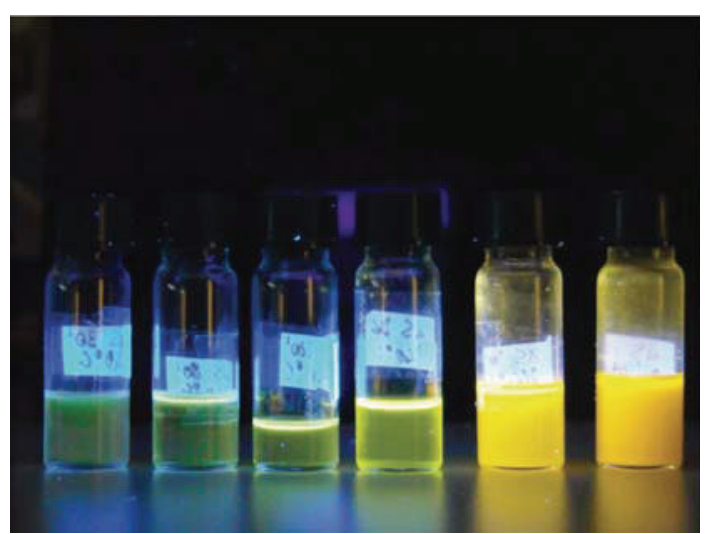

(b)

FIGURE 1: CdS nanoparticles (a) inside the polystyrene matrix and (b) in chloroform after the polymer removal. The reported samples were obtained heating a polymer/precursor foil at $300^{\circ} \mathrm{C}$ for $2,5,10,15,20$, and $30 \mathrm{~min}$ (from left to right) when different colors of the samples indicate QDs with different sizes.

an Edinburgh FLS920 spectrometer equipped with a peltier-cooled Hamamatsu R928 photomultiplier tube (185$850 \mathrm{~nm})$. An Edinburgh Xe900 $450 \mathrm{~W}$ Xenon arc lamp was used as exciting light source. The excitation wavelength was $337 \mathrm{~nm}$, and the spectra were recorded in the region between 400 and $850 \mathrm{~nm}$ using corresponding cut-off filters. The data fitting was carried out with the Origin 7 program.

The transmission electron microscopy (TEM) measurements were carried out with a FEI Tecnai F20, operated at $200 \mathrm{kV}$.

Samples' size distributions were evaluated by a Dynamic Light Scattering Analyzer (Zetasizer Nano-S, Malvern); measurements were performed using chloroform-diluted samples.

\section{Results and Discussion}

The synthesis of the $\mathrm{Cd}$ bis(thiolate) single-source precursor and CdS/polystyrene nanocomposite formation was done using quite standard procedures [10]. Single-source precursors are promising candidates for the generation of nanocomposite materials, because the stoichiometry and the homogeneous distribution of the products inside the polymer matrix are quite easy to control.

However, the in situ QDs synthesis approach needs tiny improvements regarding the presence of the polymer during optical and structural analysis. Frequently, macromolecular chains may induce errors into the final description data; therefore, the polymer must be removed a step before any kind of valuation.

This practice is necessary especially for XRD and TEM analysis, because the presence of the polymer gives rise to important undesired effects. In fact in the XRD measurements, the polystyrene broad peak is found around $20^{\circ}$, and it covers the main peak of the CdS at $26^{\circ}$ (111 plane reflection) and does not permit the use of this reflection to calculate the CdS size. Moreover, this reflection is the most intense reflection of the CdS nanoparticles and is useful for size determination of the QDs especially in the first stages of QDs formation when the other reflections are very weak.

The presence of the polymer chain is also self-defeating for the TEM analysis because the nonconductive polymer causes the charging of the samples resulting in a poor image resolution. On the contrary, when the polymer is removed, a small amount of the sample is enough to observe wellresolved images.

That's way, a second purification step was also carried out with acetone in order to remove the impurities present in the samples after the thermal annealing. These impurities come out even if the annealing procedure is carried out under vacuum, and they are probably due to the precursor degradation byproducts dissolved in the nanocomposite matrix.

To study the time and temperature dependence of the CdS QDs growth, a set of experiments covering two temperatures and different times of CdS precursor decomposition were analyzed. In particular, the precursor was annealed at $240^{\circ} \mathrm{C}$ for $30,120,180,240,300,360$, and 480 minutes and at $300^{\circ} \mathrm{C}$ (Figures $1(\mathrm{a})$ and $1(\mathrm{~b})$ ) for $2,5,10,15,20$, and 30 minutes. These two temperatures were selected, because they represent the starting $\left(240^{\circ} \mathrm{C}\right)$ and the maximum $\left(300^{\circ} \mathrm{C}\right)$ temperatures at which the decomposition of the precursor takes place $[10,11]$.

A detailed understanding of the CdS QDs growth process and kinetics is quite impossible to be done. Almost certain is the fact that the preparation of nanocrystals is strongly affected by the synthesis parameters (temperature of decomposition, precursor concentration, and time of annealing) with direct influence over the size and optical characteristics of the final particles.

In terms of kinetics, the growth of crystallite depends on the alteration of the surface energy with size. In our case, two major reaction mechanism for the CdS nanoparticles formation were taken in consideration: Ostwald's ripening and particles' aggregation. 


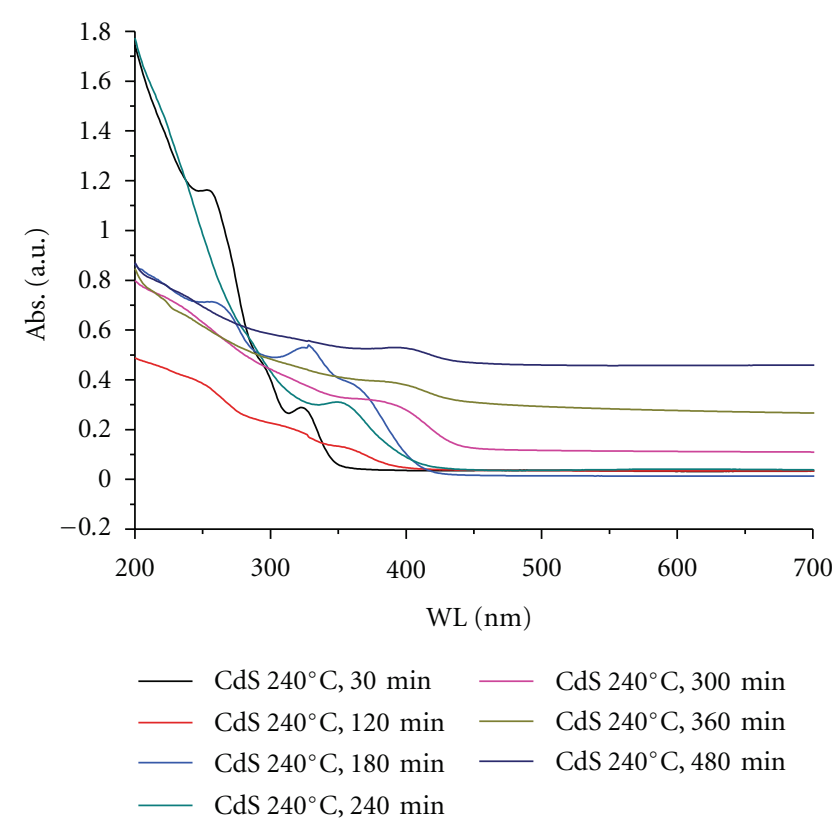

(a)
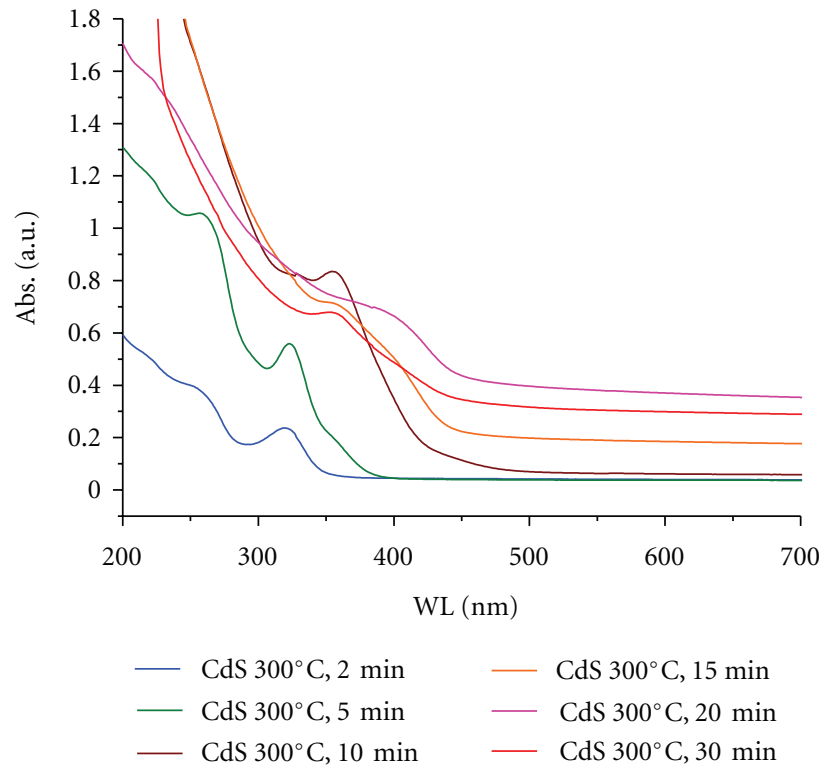

(b)

Figure 2: UV-Vis spectra of CdS nanoparticles at (a) $240^{\circ} \mathrm{C}$ and (b) $300^{\circ} \mathrm{C}$ after polymer removal. The difference of the absolute value of the absorbance is due to the different film thickness and QDs concentration.

Generally, the Ostwald ripening is believed to be the main path of crystal growth during the in situ precursor annealing. The process corresponds to a decrease of the surface free energy when large particles developed at the expense of smaller particles. However, the rate of particles ripening is governed by various parameters too (reactivity of the species, temperature of precursor annealing, etc.), that's way two time course growth of CdS nanoparticles were identified. At $300^{\circ} \mathrm{C}$, the formation of the grain is fast in respect to the inferior decomposition temperature $\left(240^{\circ} \mathrm{C}\right)$ where the rate of the nuclei formation is certainly slower. Moreover, the matrix will act as a reaction chamber in which the crystal can only grow to a certain size, preventing the coalescence of nanoparticles. Consecutively, the remove of the polymer chains could facilitate particle coalescence and probably the aggregation of the previously building units. The optical absorption spectra of the CdS nanoparticles were a fairly good indicator of all these complicated processes.

So, the UV-Vis spectra of the CdS QDs samples after polymer removal at $240^{\circ} \mathrm{C}$ (Figure 2 (a)) and $300^{\circ} \mathrm{C}$ (Figure 2(b)) illustrate the shifts of the typical CdS shoulder to higher wavelength by increasing the annealing time, as a consequence of the well-known dependence from the crystalline size due to the quantum size effect $[28,29]$. At both temperatures, the typical CdS shoulder was evidenced between 350 and $450 \mathrm{~nm}$, while, for earlier stages of QDs formation (from 30 to 180 minutes for $240^{\circ} \mathrm{C}$ and between 2 and 5 minutes for $300^{\circ} \mathrm{C}$ ), the peak around $335 \mathrm{~nm}$ was attributed to the absorption of critical nuclei $[30,31]$. In these last two conditions, a peak at around $260 \mathrm{~nm}$ is also present due to the absorption of the incompletely reacted precursor [15].
The size of CdS nanoparticles has been determined by choosing the absorption wavelength corresponding to the peak of the first derivative of these spectra (not shown) and using these values in the Brus equation. As can be seen from this time dependence isotherm curves (Figures 3(a) and 3(b)), two time course growth depending on the temperature of annealing were identified. At $300^{\circ} \mathrm{C}$, the CdS QDs size grows faster than at $240^{\circ} \mathrm{C}$ even if both of them reach a similar asymptotic value around $4.3 \mathrm{~nm}$. The shape of the curves (Figure 3 ) is similar to other typical QDs time courses reported in the literature [32, 33]: a rapid increase of the size is followed by growth rate slowing down. At molecular level, this means that at $300^{\circ} \mathrm{C}$, when the thermal degradation of the precursor reached its maximum [10], the rapid formation of the nuclei takes place until the precursor is depleted. On the other side at $240^{\circ} \mathrm{C}$, the QDs formation is slow, because this point is the initial decomposition temperature of the precursor [10]. These lines of evidences indicate that the different rate of QDs formation at $240^{\circ} \mathrm{C}$ and $300^{\circ} \mathrm{C}$ is a direct function of the precursor decomposition temperature.

Another effect of the low-temperature QDs formation is the contemporary presence of two absorption shoulders clearly observable in the UV-Vis spectra at $240^{\circ} \mathrm{C}$, especially at intermediate annealing times (between 120 and 300 minutes, Figure 2(a)). This phenomenon suggests that at $240^{\circ} \mathrm{C}$, in the same time, there is more than one population of crystallites of different sizes, indicating a defocused growth process (Ostwald ripening) [32]. On the contrary, when the temperature is higher, only one population is present (only one shoulder is evident in the QDs absorption spectra for the temperature of $300^{\circ} \mathrm{C}$, Figure $2(\mathrm{~b})$ ) due to the fact that 


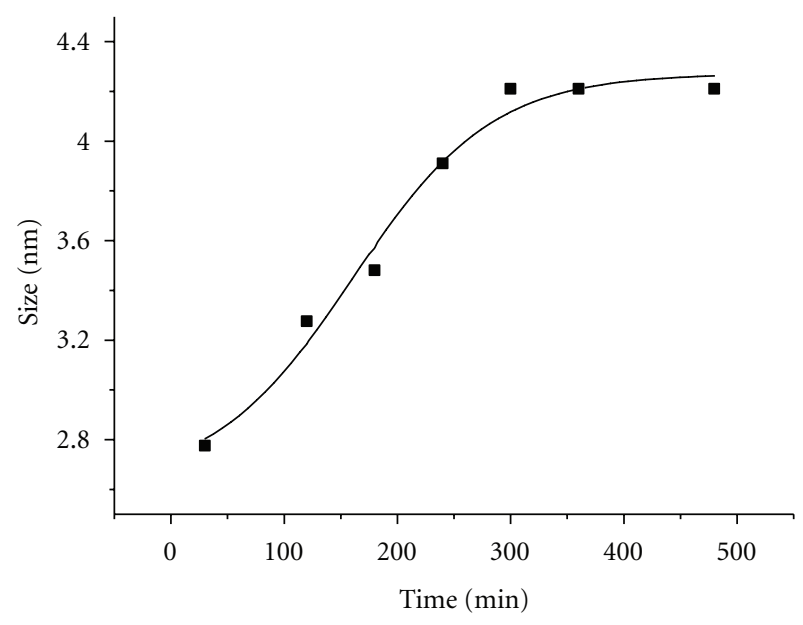

- UV-Vis size for $\mathrm{CdS} 240^{\circ} \mathrm{C}$

(a)

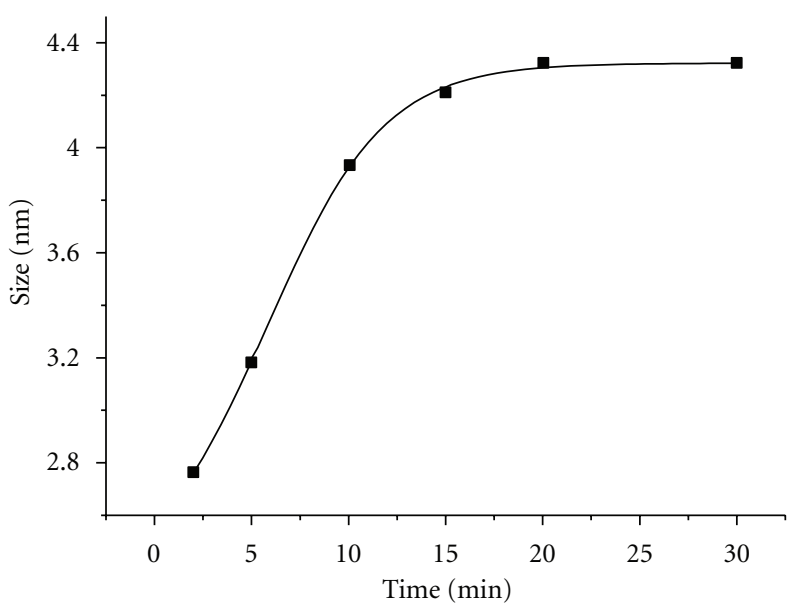

- UV size for $\mathrm{CdS} 300^{\circ} \mathrm{C}$

(b)

Figure 3: Time dependence of size for the CdS QDs sample annealed at (a) $240^{\circ} \mathrm{C}$ and (b) $300^{\circ} \mathrm{C}$.

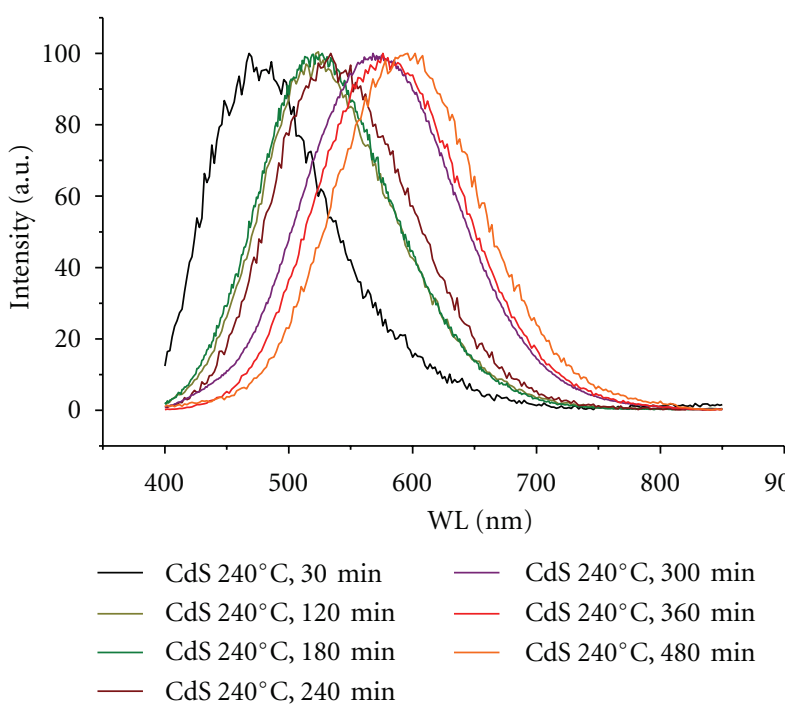

(a)

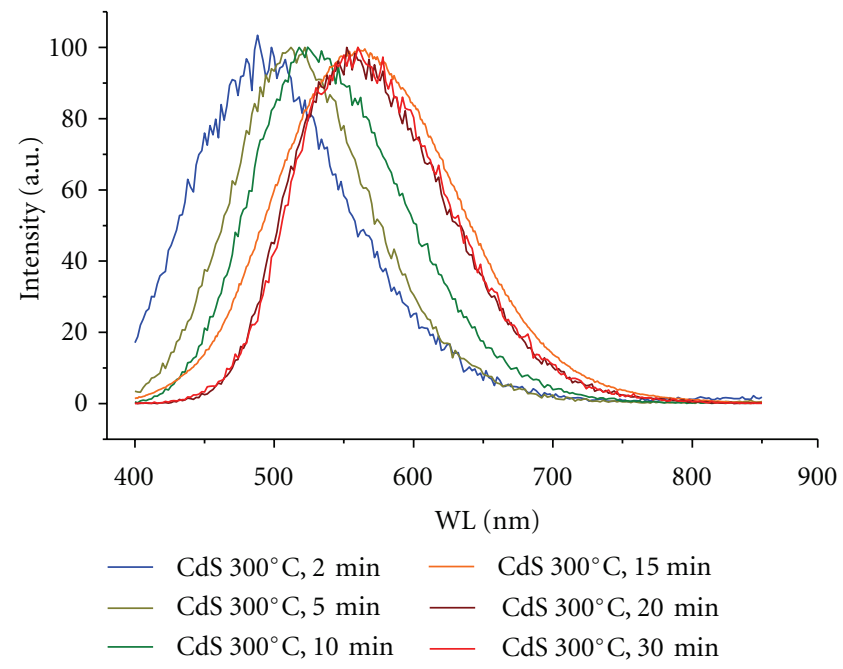

(b)

Figure 4: PL spectra of CdS samples at (a) $240^{\circ} \mathrm{C}$ and (b) $300^{\circ} \mathrm{C}$. The PL emissions of the nanoparticles were obtained with an excitation wavelength of $337 \mathrm{~nm}$.

the decomposition is faster and two different crystalline size cannot coexist into each samples.

The PL spectra too (Figures $4(\mathrm{a})$ and $4(\mathrm{~b})$ ) confirm the general trend, indicating that the emission maxima are shifted towards higher wavelengths when the samples are annealed for longer time (QDs size increase). The enhancement of the PL maximum wavelength with a corresponding increase of QDs size is a well known phenomenon [34, 35]; however, it's quantitative theoretical interpretation (i.e., quantitative relationship between the wavelength emission maximum and QDs size) is not obvious. In fact the PL emission in semiconductor QDs can be considered as a complex combination of the band-edge, deep traps (internal crystal defects), surface state emissions (surface defects) [36] and size distribution of the analyzed samples $[21,22,37$, 38]. Due to this difficult theoretical interpretation, the PL signal was correlated with the size values obtained from UVVis spectra (Figure 5). In such a way the obtained curves, logistic fitting with (1), can be utilized as a tool for size determination starting from PL emission:

$$
\text { Size }=A_{2}+\frac{\left(A_{1}-A_{2}\right)}{\left[1+\left(\lambda / \lambda_{0}\right)^{p}\right]} .
$$

The fitting curve has employed a logistic model with the subsequent parameters: $A_{1}=2.7809, A_{2}=4.1878, \lambda_{0}=$ $526.2519, p=87.4905$ for the $240^{\circ} \mathrm{C}$ curve and $A_{1}=2.7629$, $A_{2}=4.2030, \lambda_{0}=515.9854, p=76.3936$ for the $300^{\circ} \mathrm{C}$ curve, respectively. 


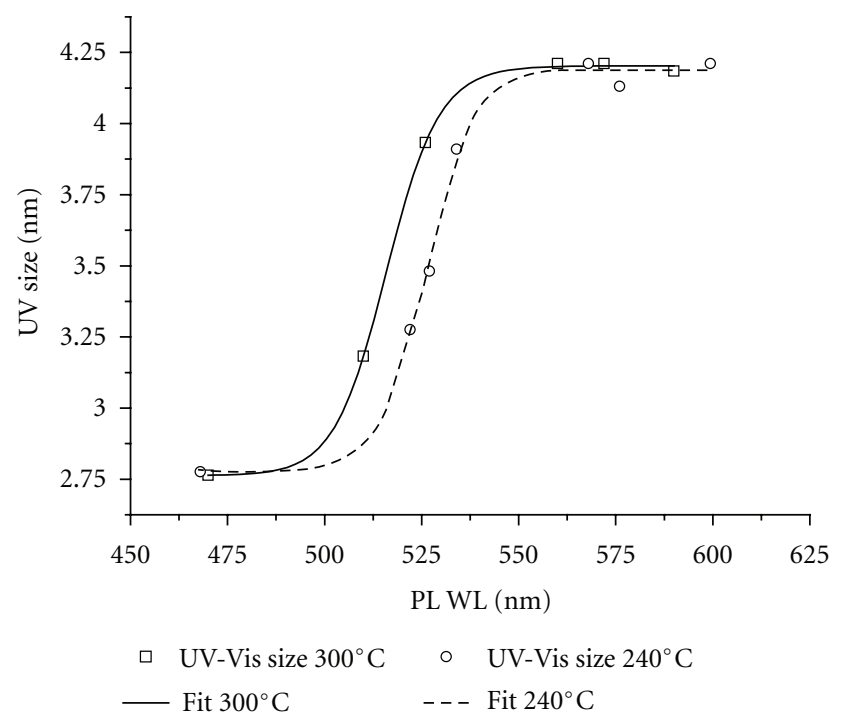

FIGURE 5: Correlation between the sizes obtained from UV-Vis spectra and the emission wavelength (WL) of the QDs synthesized in the nanocomposites at (a) $240^{\circ} \mathrm{C}$ (broken line) and (b) $300^{\circ} \mathrm{C}$ (solid line).

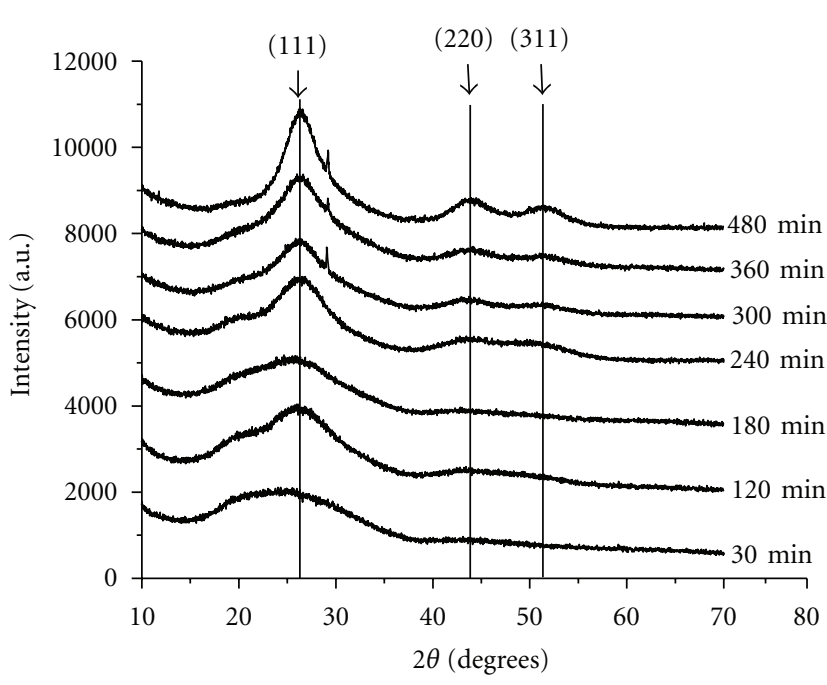

(a)

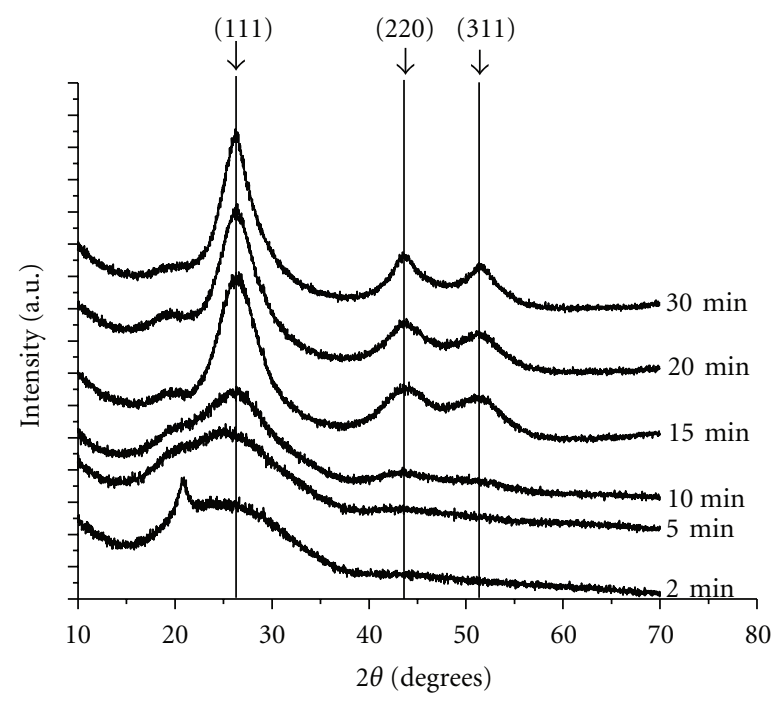

(b)

FIGURE 6: XRD spectra of CdS nanoparticles annealed at (a) $240^{\circ} \mathrm{C}$ and (b) $300^{\circ} \mathrm{C}$. The vertical lines indicate the angular position of the reflections and in parenthesis are reported the Miller indices.

Another important consideration of the PL spectra is the band broadening which depends from the QDs size distribution $[21,22,37,38]$ and from the defects of the QDs crystallographic structure [36, 37]. QDs having a wellfocused size distribution without any crystal defect will show a sharp PL emission, while nanocrystals displaying broad size distribution and crystal defects will exhibit a luminescence signal broadening. In the present case, the average band broadening is $110 \pm 7.9 \mathrm{~nm}\left(\right.$ at $300^{\circ} \mathrm{C}$ ) and $110 \pm 6.0 \mathrm{~nm}$ (at $240^{\circ} \mathrm{C}$ ), which is generally larger in respect to other literature systems (around $20 \mathrm{~nm}$ ) [21, 22, 37, 38] suggesting probably the presence of QDs with some crystal defects.
Figure 6 shows the XRD analysis of the CdS samples annealed at $240^{\circ} \mathrm{C}$ between 30 and 480 minutes (Figure 6(a)) and at $300^{\circ} \mathrm{C}$ in the interval 2-30 minutes (Figure 6(b)) after the removal of the polymer. The samples treated at $240^{\circ} \mathrm{C}$ display three main peaks at $26.433^{\circ}, 44.239^{\circ}$, and $51.545^{\circ}$ angular positions and the phase analysis reveals the presence of a cubic phase for CdS QDs (card no. 002-0454, PDF2 Database JCPDS-ICCD2000). The absence of the peaks at $28.4^{\circ}$ and $53^{\circ}$, which are associated only with hexagonal phase, eliminates the possibility to incorporate the hexagonal phase of CdS in the samples. The same behavior has been achieved at $300^{\circ} \mathrm{C}$ where the peaks with angular reflections 


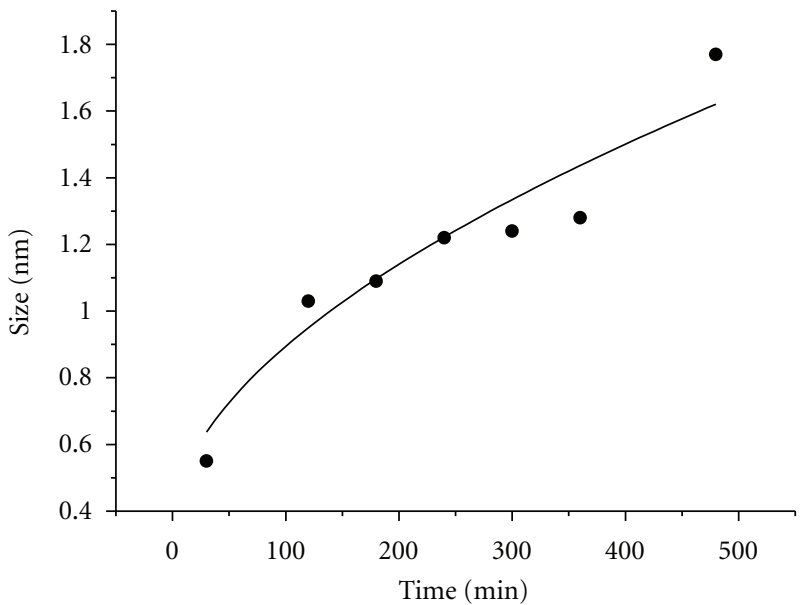

- XRD size for CdS $240^{\circ} \mathrm{C}$

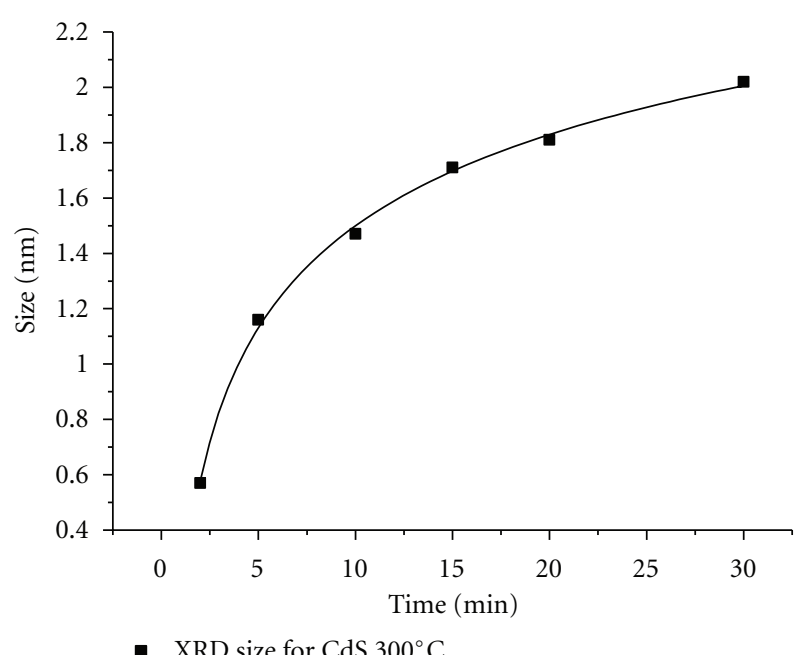

- XRD size for $\mathrm{CdS} 300^{\circ} \mathrm{C}$

(a)

(b)

Figure 7: QDs sizes from Scherrer equation as a function of time for sample at (a) $240^{\circ} \mathrm{C}$ and (b) $300^{\circ} \mathrm{C}$. The logistic curve was used to fit the data.

at $26.300^{\circ}, 43.654^{\circ}$, and $51.479^{\circ}$ reveal a cubic crystalline structure of the CdS QDs too.

The average size of the nanoparticles was calculated using the Scherer equation, based on 111 reflection $\left(2 \theta=26.433^{\circ}\right)$ because it is more evident for all the samples (Figures 7(a) and $7(\mathrm{~b}))$. A growth behaviour related to that found in the UV-Vis analysis was also identified.

The crystal structure of the CdS nanoparticles was investigated using electron microscopy (TEM measurements). For example, Figure 8 shows the HRTEM image of the sample annealed at $300^{\circ} \mathrm{C}$ for 10 minutes. Several CdS crystalline nanoparticles were visible, and most of them presented a cubic phase, as suggested by XRD data, too. Moreover, the characteristic lattice fringes of the cubic lattice phase were clearly observed from the HRTEM photograph of CdS nanoparticles. In Figure 8, for one CdS QD, the direction and spacing of the crystal planes (111) were also indicated.

The TEM images were used to estimate the average size of the clusters for the different annealing conditions. Figure 9 (a) shows the histograms of the particle size distributions for samples annealed at $240^{\circ} \mathrm{C}(120,240$, and 480 minutes) and $300^{\circ} \mathrm{C}(5,10$, and 20 minutes $)$, respectively. The width of the distributions is relatively large, more than around 30\%, indicating that the QDs are not monodispersed. The size distribution has been fit using a Gaussian function: the average QD dimension estimated by the position $d$ of the peak and the error as half the full width at half maximum $w$. Figure 9(b) illustrates a plot of the average dimension of the CdS clusters as a function of the annealing time for $240^{\circ} \mathrm{C}$ and $300^{\circ} \mathrm{C}$. For the $240^{\circ} \mathrm{C}$ temperature, the size of the nanoparticles increases with the annealing time from $2.6 \pm 0.6 \mathrm{~nm}$ at 120 minutes up to $3.3 \pm 1.7 \mathrm{~nm}$ at 480 minutes. For the reaction temperature of $300^{\circ} \mathrm{C}$, larger clusters were observed, with average dimension ranging from $3.2 \pm 1.4 \mathrm{~nm}$ at 5 minutes up to $4.6 \pm 2.1 \mathrm{~nm}$ at 20 minutes. All these

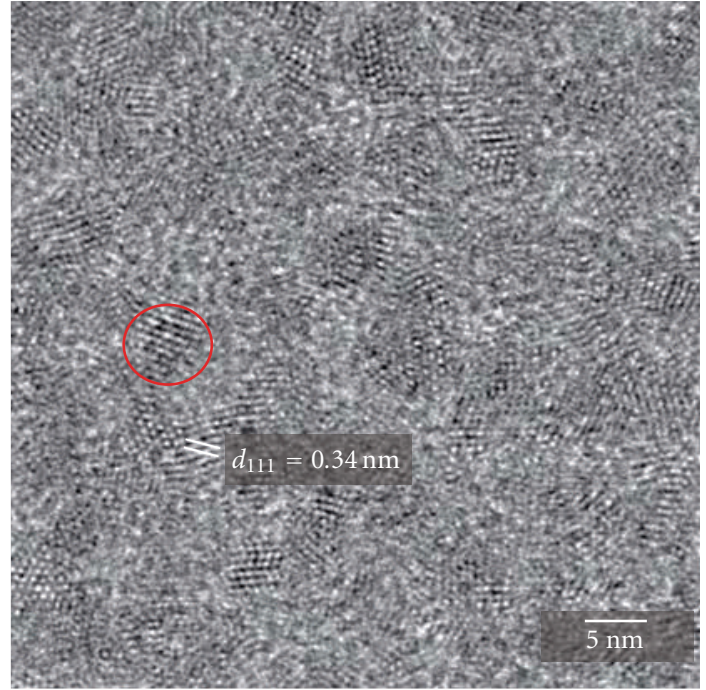

Figure 8: HRTEM image of the sample annealed at $300^{\circ} \mathrm{C}$ for 10 minutes. Several small crystalline nanoparticles of CdS are visible embedded in the amorphous polymer (one is highlighted with a red circle). For one CdS particle, of cubic phase, the orientation and interplanar distance corresponding to $d_{111}=0.34 \mathrm{~nm}$ are highlighted.

dimensions seem to be approximately comparable with the CdS sizes determined by the UV-Vis technique (Table 1). The UV-Vis and TEM measurements illustrate that optical data are in good agreement with electron microscopy and therefore represent an optimal way of size evaluation.

It is interesting to note that the grain size estimated by XRD data (using the Scherrer's formula) is smaller as compared to the size observed by TEM micrographs (Table 1). Even if the nanoparticles growth process has 
TABLE 1: Summary of CdS QDs sizes obtained from XRD, UV-Vis, HRTEM, and DLS measurements for sample annealed at $240^{\circ} \mathrm{C}(120$, $240,480$ minutes $)$ and at $300^{\circ} \mathrm{C}(5,10,20$ minutes $)$.

\begin{tabular}{lccccc}
\hline $\begin{array}{l}\text { Annealing temperature } \\
\text { Annealing time }\end{array}$ & $120 \mathrm{~min}$ & $240 \mathrm{~min}$ & $480 \mathrm{~min}$ & $5 \mathrm{~min}$ & $300^{\circ} \mathrm{C}$ \\
\hline XRD size & $1.0 \mathrm{~nm}$ & $1.2 \mathrm{~nm}$ & $1.8 \mathrm{~nm}$ & $1.2 \mathrm{~nm}$ & $1.5 \mathrm{~nm}$ \\
UV-Vis size & $3.3 \mathrm{~nm}$ & $3.4 \mathrm{~nm}$ & $4.2 \mathrm{~nm}$ & $3.4 \mathrm{~nm}$ & $3.8 \mathrm{~nm}$ \\
TEM size & $2.6 \mathrm{~nm}$ & $2.9 \mathrm{~nm}$ & $3.3 \mathrm{~nm}$ & $3.2 \mathrm{~nm}$ & $3.7 \mathrm{~nm}$ \\
\hline
\end{tabular}
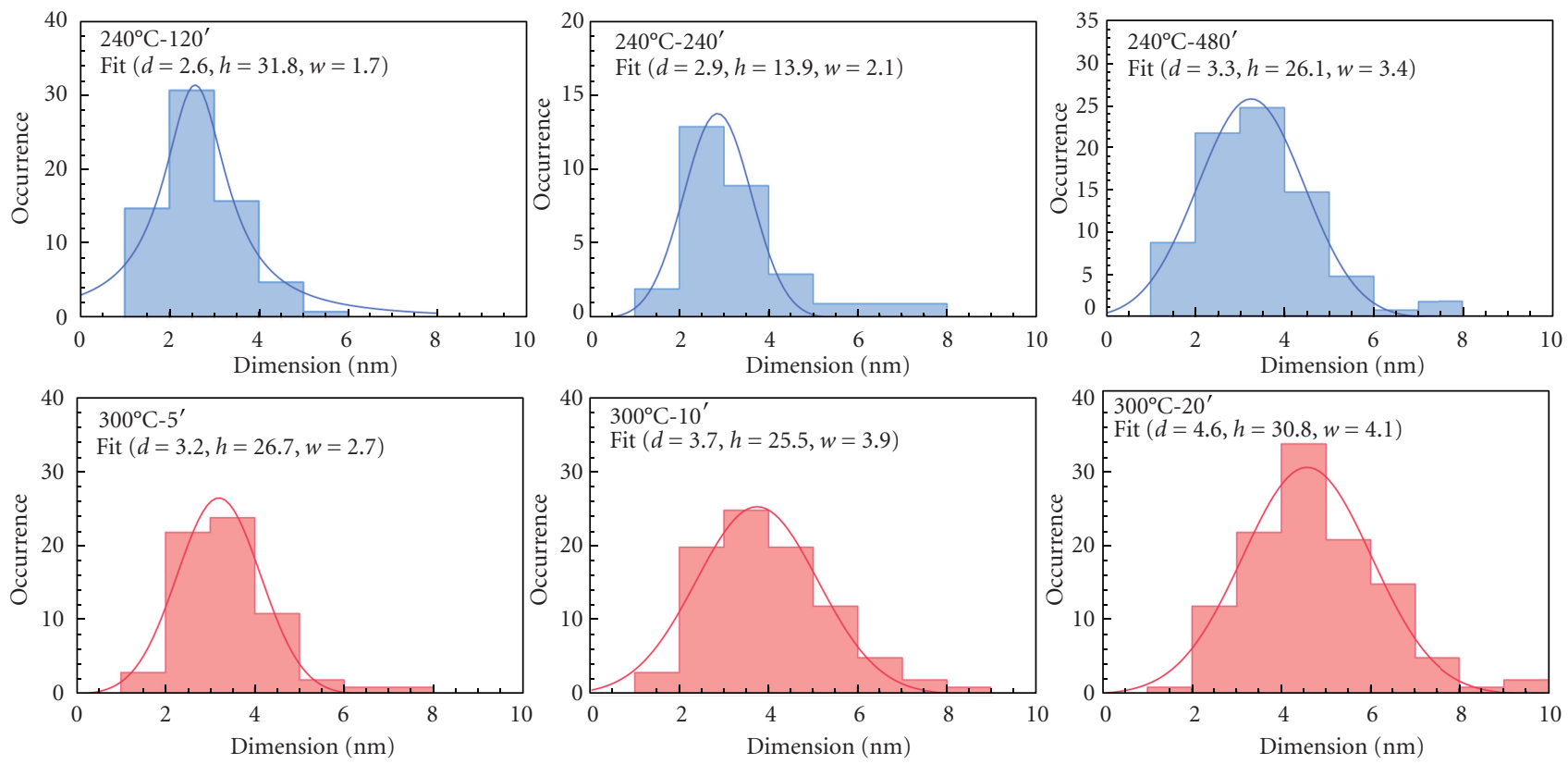

(a)

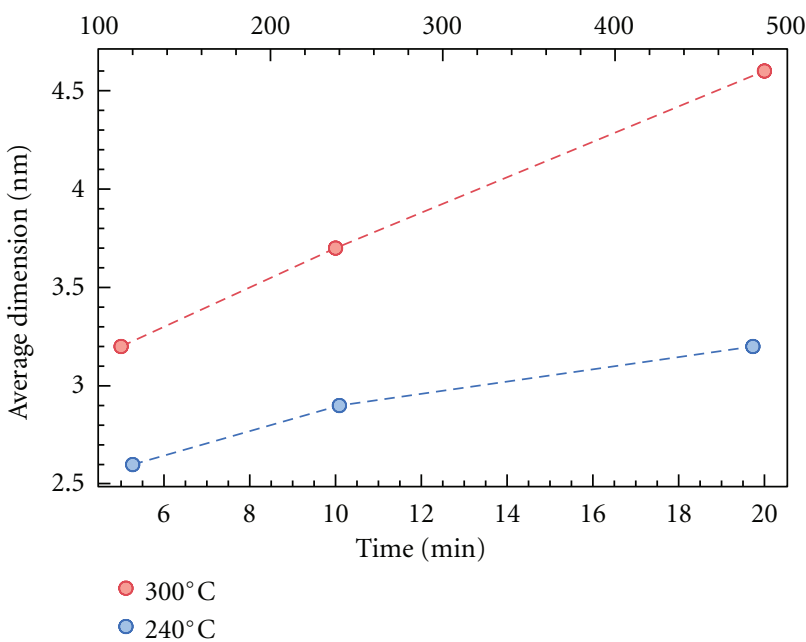

(b)

FIGURE 9: (a) Histograms of the particles sizes as a function of the annealing time and temperature with Gaussian fit functions, (b) plot of the variation of the dimension of the CdS nanoparticles as a function of the annealing time.

a comparable tendency (the order of magnitude is similar) the sizes calculated for CdS QDs within both analyses do not match accurately. This discrepancy between the values is not so surprising as soon as it was observed by a number of experimental studies too $[39,40]$.
As already reported in the literature, TEM investigation is based on the difference between the visible grain boundaries, while the XRD analysis provide information of the average crystallite size (coherently diffracting domains), which is usually much smaller as compared to that observed by any 


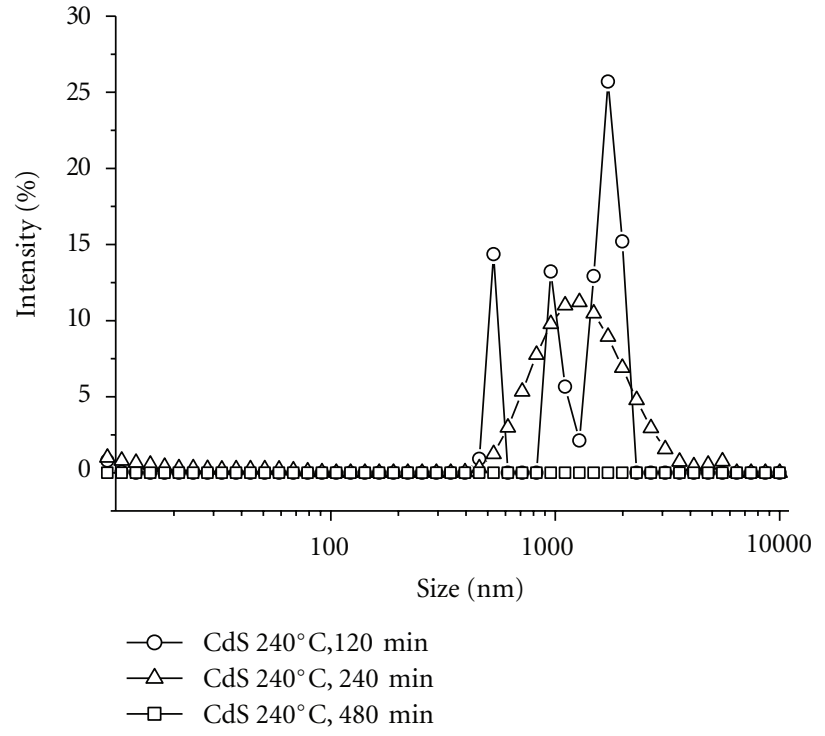

(a)

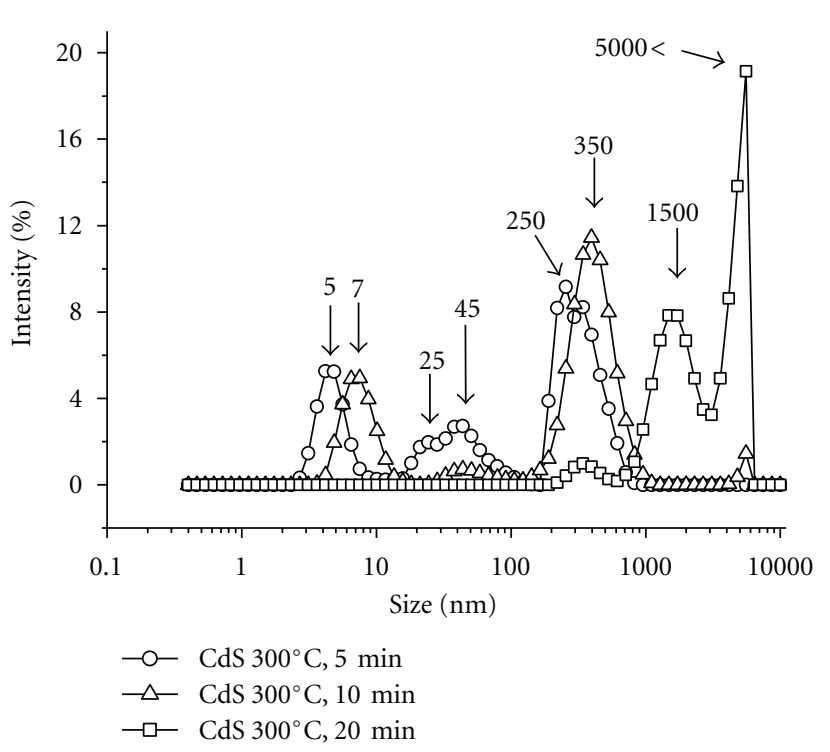

(b)

FIgURE 10: DLS analysis of CdS nanoparticles treated at (a) $240^{\circ} \mathrm{C}$ and (b) $300^{\circ} \mathrm{C}$ for different times of annealing.

direct method (including TEM). Furthermore, the grain size evaluation provided by XRD method is accompanied by a peak broadening (full width at half maximum of the diffraction peaks) which influence considerably the final size number. This peak enlargement is a result of the various contributions regarding the instrumental broadening effect, lattice strain, or other lattice defects of the particle. Even if several correction methods of the XRD profiles are already available in the literature, none of them can take care of all these contributions because the structure of the CdS nanoparticles is quite complex with direct influence on the XRD profiles and important effects on the final CdS QDs size (indirect approximation of the particle sizes via the full width at half maximum of the most intense peak).

In order to quantify the characteristic microscopic features of the QDs samples, dynamic light scattering (DLS) analysis was also carried out. The DLS measurements allow the determination of the particle size in solution, involving translational diffusion coefficient by using the Stokes-Einstein equation [40]. For example, at $240^{\circ} \mathrm{C}$ after 120 and 240 minutes of annealing, it seems that the particles have a size distribution between 0.5 and $2 \mu \mathrm{m}$, while after 480 minutes of annealing, no particles were detected, probably because they are to big for the sensitivity of the instrument (Figure $10(\mathrm{a})$ ). At $300^{\circ} \mathrm{C}$ the DLS diagram is more structured, suggesting that the particles are better resuspended in the solvent. In fact after 5 minutes of annealing (Figure 10(b)), three main peaks were observed and were correlated to particles with diameter of $5 \mathrm{~nm}, 20$ $80 \mathrm{~nm}$, and 200-800 nm, correspondingly. Moreover, after 10 minutes of thermal annealing, particles became bigger (two peaks at $7 \mathrm{~nm}$ and $200-1000 \mathrm{~nm}$ ), while, after 20 minutes, only particles of $1.5 \mu \mathrm{m}$ or bigger were evidenced.
The DLS data seems to indicate the same trend for the growth process too (increase of the particles size as a function of the annealing time) but with absolute values higher than those obtained from other structural characterization methods (Table 1). Even if this information is seemingly in contrast with others, the phenomenon could be explained considering that the QDs in solution tend to aggregate forming clusters. We assume that the aggregation of the QDs is due to the interaction of the surface of several nanoparticles partially covered by the organic material's either polymeric or residual alkylic chain. At higher annealing times, the formation of the clusters shifts toward the growth of microcrystals (more than 1-2 microns).

Another important aspect affecting the enhanced measured size is correlated with the fact that the DLS analysis reflects the diffusion of a particle within a fluid so refers to a hydrodynamic diameter [41]. Therefore, the diameter that is obtained by this technique will depend not only on the size of the particle "core" but also on the coordination sphere and on the species adsorbed on the particle surface. Any change on the surface of a particle (polystyrene chains or particles aggregation into microcrystal) will overestimate the particle size.

\section{Conclusions}

Luminescent CdS nanoparticles have been successfully grown in situ within a polystyrene matrix using the thermolytical treatment of a single-source precursor $[\mathrm{Cd}$ bis(thiolate)] inside a polystyrene foil. These experiments were performed at two fixed temperatures, namely, $240^{\circ} \mathrm{C}$ and $300^{\circ} \mathrm{C}$, for different times of annealing when it was evidenced a size dependence of the CdS nanoparticles from the reaction's time. 
The XRD data revealed that the synthesized CdS nanoparticles have the cubic structure of the bulk CdS. Additionally, the UV-Vis spectra evidence a steady increase in particles size as a function of time when the typical CdS QDs absorption shifts to higher wavelength as a consequence of the increase of the annealing time. The size of the QDs calculated with the Brus equation is compared with that obtained making use of Scherrer's formula even if the two values do not agree closely. Instead, optical data are in good agreement with electron microscopy (HRTEM) and represent an optimal way of size evaluation. The wavelength shift of the PL spectra as a function of particle size was also observed.

Furthermore, the DLS measurements of the CdS nanoparticles behaviour in solution illustrated that, for longer times of annealing, the QDs tend to aggregate into microcrystals, with diameters biased towards larger values.

\section{Acknowledgments}

The presented work has received funding from the European Community's Seventh Framework Programme (FP7/20072013) under Grant Agreement number 247928. The authors gratefully thank the Dr. Stefania Albonetti for her support in measurements' organization.

\section{References}

[1] D. Y. Godovsky, "Device applications of polymer-nanocomposites," Advances in Polymer Science, vol. 153, pp. 163-205, 2000.

[2] D. R. Paul and L. M. Robeson, "Polymer nanotechnology: nanocomposites," Polymer, vol. 49, no. 15, pp. 3187-3204, 2008.

[3] M. Muccini, "A bright future for organic field-effect transistors," Nature Materials, vol. 5, no. 8, pp. 605-613, 2006.

[4] A. L. Rogach, N. Gaponik, J. M. Lupton et al., "Lightemitting diodes with semiconductor nanocrystals," Angewandte Chemie, vol. 47, no. 35, pp. 6538-6549, 2008.

[5] W. U. Huynh, J. J. Dittmer, and A. P. Alivisatos, "Hybrid nanorod-polymer solar cells," Science, vol. 295, no. 5564, pp. 2425-2427, 2002.

[6] P. L. Ong and I. A. Levitsky, "Organic / IV, III-V semiconductor hybrid solar cells," Energies, vol. 3, no. 3, pp. 313-334, 2010.

[7] S. Nie, Y. Xing, G. J. Kim, and J. W. Simons, "Nanotechnology applications in cancer," Annual Review of Biomedical Engineering, vol. 9, pp. 257-288, 2007.

[8] M. E. Åkerman, W. C. W. Chan, P. Laakkonen, S. N. Bhatia, and E. Ruoslahti, "Nanocrystal targeting in vivo," Proceedings of the National Academy of Sciences of the United States of America, vol. 99, no. 20, pp. 12617-12621, 2002.

[9] H. C. Leventis, S. P. King, A. Sudlow, M. S. Hill, K. C. Molloy, and S. A. Haque, "Nanostructured hybrid polymer-inorganic solar cell active layers formed by controllable in situ growth of semiconducting sulfide networks," Nano Letters, vol. 10, no. 4, pp. 1253-1258, 2010.

[10] F. Antolini, T. Di Luccio, A. M. Laera et al., "Direct synthesis of II-VI compound nanocrystals in polymer matrix," Physica Status Solidi, vol. 244, no. 8, pp. 2768-2781, 2007.
[11] T. Di Luccio, A. M. Laera, L. Tapfer, S. Kempter, R. Kraus, and B. Nickel, "Controlled nucleation and growth of CdS nanoparticles in a polymer matrix," Journal of Physical Chemistry B, vol. 110, no. 25, pp. 12603-12609, 2006.

[12] F. Antolini, A. Ghezelbash, C. Esposito, E. Trave, L. Tapfer, and B. A. Korgel, "Laser-induced nanocomposite formation for printed nanoelectronics," Materials Letters, vol. 60, no. 8, pp. 1095-1098, 2006.

[13] A. Athanassiou, R. Cingolani, E. Tsiranidou et al., "Photoninduced formation of CdS nanocrystals in selected areas of polymer matrices," Applied Physics Letters, vol. 91, no. 15, Article ID 153108, 2007.

[14] D. Fragouli, P. P. Pompa, M. Kalyva et al., "The effect of irradiation wavelength on the quality of CdS nanocrystals formed directly into PMMA matrix," Journal of Physical Chemistry C, vol. 114, no. 33, pp. 13985-13990, 2010.

[15] D. Fragouli, A. M. Laera, G. Caputo et al., "The effect of polymer matrices in the in-situ cds formation under uv irradiation of precursor-polymer films," Journal of Nanoscience and Nanotechnology, vol. 10, no. 2, pp. 1267-1272, 2010.

[16] F. Antolini, C. Esposito, E. Trave, and L. Tapfer, Italian Patent no. MI2006A001156.

[17] Z. Sedaghat, N. Taghavinia, and M. Marandi, "Thermal control of the size and crystalline phase of CdS nanoparticles," Nanotechnology, vol. 17, no. 15, article 034, pp. 3812-3816, 2006.

[18] S. Kumar and R. Chandra, "Temperature dependent studies of CdS nanoparticles in viscous matrix," Optical Materials, vol. 27, no. 8, pp. 1346-1349, 2005.

[19] G. G. Yordanov, C. D. Dushkin, G. D. Gicheva, B. H. Bochev, and E. Adachi, "Synthesis of high-quality semiconductor nanoparticles in a composite hot-matrix," Colloid and Polymer Science, vol. 284, no. 2, pp. 229-232, 2005.

[20] S. Q. Sun and T. Li, "Synthesis and characterization of CdS nanoparticles and nanorods via solvo-hydrothermal route," Crystal Growth and Design, vol. 7, no. 11, pp. 2367-2371, 2007.

[21] X. G. Peng, J. Wickham, and A. P. Alivisatos, "Kinetics of II-VI and III-V colloidal semiconductor nanocrystal growth: 'Focusing' of size distributions," Journal of the American Chemical Society, vol. 120, no. 21, pp. 5343-5344, 1998.

[22] C. S. Yang, D. D. Awschalom, and G. D. Stucky, "Kineticdependent crystal growth of size-tunable CdS nanoparticles," Chemistry of Materials, vol. 13, no. 2, pp. 594-598, 2001.

[23] H. Tong and Y. J. Zhu, "Synthesis of CdS nanocrystals based on low-temperature thermolysis of one single-source organometallic precursor," Nanotechnology, vol. 17, no. 3, pp. 845-851, 2006.

[24] D. Kim, T. Mishima, K. Tomihira, and M. Nakayama, "Temperature dependence of photoluminescence dynamics in colloidal CdS quantum dots," Journal of Physical Chemistry C, vol. 112, no. 29, pp. 10668-10673, 2008.

[25] S. Krumm, "WINFIT 1.0-A computer program for X-ray diffraction line profile analysis," in Proceedings of the 13th Conference on Clay Mineralogy and Petrology Acta Universitatis Carolinae Geologica, vol. 38, pp. 253-261, 1994.

[26] L. Brus, "Electronic wave functions in semiconductor clusters: experiment and theory," Journal of Physical Chemistry, vol. 90, no. 12, pp. 2555-2560, 1986.

[27] D. Ingert, L. Motte, and M. P. Pileni, CdS and CdTe Nanoparticles Made in Reverse Micelles: Preparation Modes and Optical Properties Fine Particles: Synthesis Characterization and Mechanisms of Growth, edited by T. Sugimoto, Marcel Dekker, New York, NY, USA, 1999. 
[28] S. P. Gubin, N. A. Kataeva, and G. B. Khomutov, "Promising avenues of research in nanoscience: chemistry of semiconductor nanoparticles," Russian Chemical Bulletin, vol. 54, no. 4, pp. 827-852, 2005.

[29] S. V. Gaponenko, Cambridge Studies in Modern Optics. Optical Properties of Semiconductor Nanocrystals, Cambridge University, Cambridge, UK, 1998.

[30] D. Pan, X. Ji, L. An, and Y. Lu, "Observation of nucleation and growth of CdS nanocrystals in a two-phase system," Chemistry of Materials, vol. 20, no. 11, pp. 3560-3566, 2008.

[31] D. Pan, S. Jiang, L. An, and B. Jiang, "Controllable synthesis of highly luminescent and monodisperse CdS nanocrystals by a two-phase approach under mild conditions," Advanced Materials, vol. 16, no. 12, pp. 982-985, 2004.

[32] Y. Yin and A. P. Alivisatos, "Colloidal nanocrystal synthesis and the organic-inorganic interface," Nature, vol. 437, no. 7059, pp. 664-670, 2005.

[33] C. Ribeiro, E. J. H. Lee, E. Longo, and E. R. Leite, "A Kinetic model to describe nanocrystal growth by the oriented attachment mechanism," ChemPhysChem, vol. 6, no. 4, pp. 690-696, 2005.

[34] M. Nirmal and L. Brus, "Luminescence photophysics in semiconductor nanocrystals," Accounts of Chemical Research, vol. 32, no. 5, pp. 407-414, 1999.

[35] X. Michalet, F. Pinaud, T. D. Lacoste et al., "Properties of fluorescent semiconductor nanocrystals and their application to biological labeling," Single Molecules, vol. 2, no. 4, pp. 261276, 2001.

[36] N. Chestnoy, T. D. Harris, R. Hull, and L. E. Brus, "Luminescence and photophysics of CdS semiconductor clusters: the nature of the emitting electronic state," Journal of Physical Chemistry, vol. 90, no. 15, pp. 3393-3399, 1986.

[37] W. W. Yu and X. Peng, "Formation of high-quality CdS and other II-VI semiconductor nanocrystals in noncoordinating solvents: tunable reactivity of monomers," Angewandte Chemie, vol. 41, no. 13, pp. 2368-2371, 2002.

[38] C. B. Murray, D. J. Norris, and M. G. Bawendi, "Synthesis and characterization of nearly monodisperse $\mathrm{CdE}(\mathrm{E}=\mathrm{S}$, Se, Te) semiconductor nanocrystallites," Journal of the American Chemical Society, vol. 115, no. 19, pp. 8706-8715, 1993.

[39] H. Weller, "Colloidal semiconductor Q-particles: chemistry in the transition region between solid state and molecules," Angewandte Chemie, vol. 32, no. 1, pp. 41-53, 1993.

[40] S. K. Vajpai, R. K. Dube, and M. Sharma, "Studies on the mechanism of the structural evolution in $\mathrm{Cu}-\mathrm{Al}-\mathrm{Ni}$ elemental powder mixture during high energy ball milling," Journal of Materials Science, vol. 44, no. 16, pp. 4334-4341, 2009.

[41] Dynamic Light Scattering: an introduction in 30 minutes, Technical Note, Malvern Instruments. 

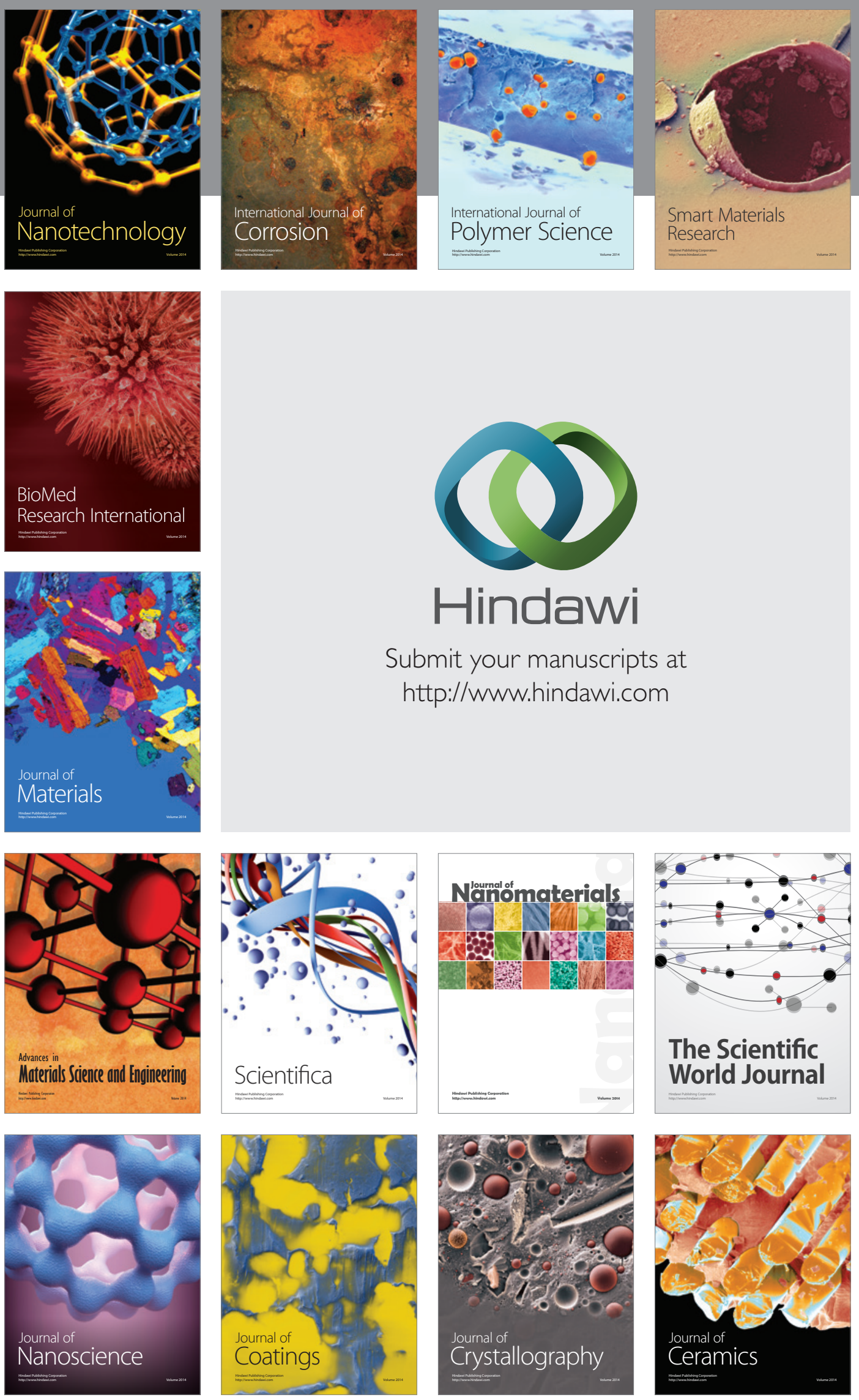

The Scientific World Journal

Submit your manuscripts at

http://www.hindawi.com

\section{World Journal}

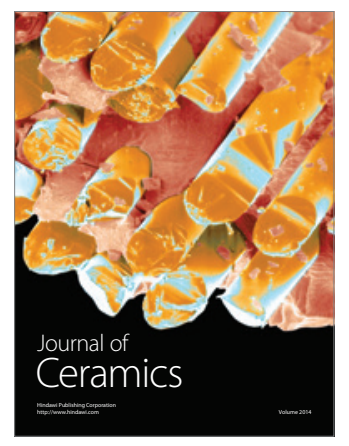

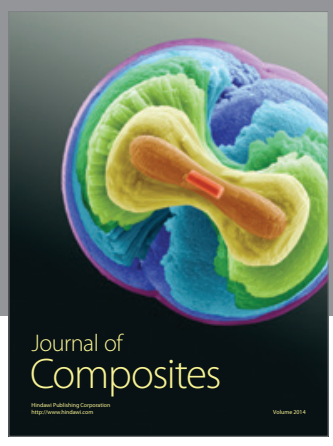
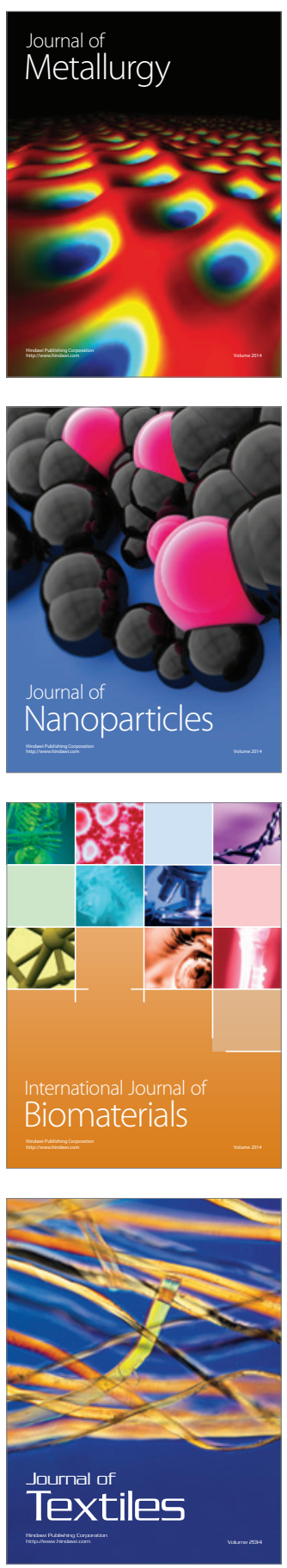